\title{
Parents' Safety Beliefs and Childhood Agricultural Injury
}

\author{
Muree Larson-Bright, $\mathrm{PhD},{ }^{1}$ Susan G. Gerberich, $\mathrm{PhD}^{1}{ }^{1}$ Ann S. Masten, $\mathrm{PhD}^{2}$ \\ Bruce H. Alexander, PhD, ' James G. Gurney, PhD, ${ }^{3}$ Timothy R. Church, PhD, ${ }^{1}$ \\ Andrew D. Ryan, ${ }^{M s},{ }^{1}$ and Colleen M. Renier, Bs $^{4}$
}

\begin{abstract}
Background This study examined potential associations between parental safety beliefs and children's chore assignments or risk of agricultural injury.

Methods Analyses were based on nested case-control data collected by the 1999 and 2001 Regional Rural Injury Study-II (RRIS-II) surveillance efforts. Cases ( $n=425$, reporting injuries) and controls ( $n=1,886$, no injuries; selected using incidence density sampling) were persons younger than 20 years of age from Midwestern agricultural households. A causal model served as the basis for multivariate data analysis.

Results Decreased risks of injury (odds ratio [OR] and 95\% confidence intervals [CI]) were observed for working-aged children with "moderate," compared to "very strict" parental monitoring $(0.60 ; 0.40-0.90)$, and with parents believing in the importance of physical (0.80; 0.60-0.95) and cognitive readiness $(0.70,0.50-0.90$, all children; 0.30, $0.20-0.50$, females) when assigning new tasks. Parents' safety beliefs were not associated with chore assignments.

Conclusions Parents' safety beliefs were associated with reduced risk of childhood agricultural injury; the association was not mediated by chore assignments. Am. J. Ind. Med. 52:724-733, 2009. ๑ 2009 Wiley-Liss, Inc.
\end{abstract}

KEY WORDS: child/adolescent; injury; agriculture; parents' safety beliefs; work practices

\footnotetext{
${ }^{1}$ Regional Injury Prevention Research Center, Division of Environmental Health Sciences, School of Public Health, University of Minnesota, Minneapolis, Minnesota

${ }^{2}$ Institute of Child Development, University of Minnesota, Minneapolis, Minnesota

${ }^{3}$ Child Health Evaluation and Research Unit, Department of Pediatrics, University of Michigan, Ann Arbor, Michigan

${ }^{4}$ Division of Education and Research, St. Mary's/Duluth Clinic Health System, Duluth, Minnesota

Contract grant sponsor: National Institute for Occupational Safety and Health (NIOSH), Centers for Disease Control and Prevention, Department of Health and Human Services; Contract grant numbers: R01 CCR514375, R01 OH04270; Contract grant sponsor: Occupational Injury Prevention Research Training Program, National Occupational Research Agenda Program, Midwest Center for Occupational Health and Safety (NIOSH); Contract grant number: T42/CCT510-422; Contract grant sponsor: University of Minnesota, Minneapolis, Minnesota, U.S.A..

${ }^{*}$ Correspondence to: Susan G. Gerberich, Regional Injury Prevention Research Center, Division of Environmental Health Sciences, School of Public Health, University of Minnesota, Mayo Mail Code 807, 420 Delaware St. SE, Minneapolis, MN 55455.

E-mail: gerbe001@umn.edu
}

Accepted 18 May 2009

DOl 10.1002/ajim.20719. Published online in Wiley InterScience

(www.interscience.wiley.com)

\section{INTRODUCTION}

In the home environment, children's injuries are believed to be preventable through supervision around potential hazards [Morrongiello and House, 2004; Morrongiello et al., 2001, 2006] and through injury socializationteaching children to recognize and avoid hazards [Peterson and Stern, 1997]. In the work environment, regulations and standards limit hazardous exposures and keep children safe. Family agricultural operations are mostly exempt from federal labor and safety regulations and are not afforded this protection [USDOL, 1984; Kelsey, 1994]. In the United States, parents are primarily responsible for regulating the hazards encountered by the 1.5 million children, younger than 20 years old, who live and work on agricultural operations [Hendricks et al., 2005]. To help parents assess the developmental appropriateness of agricultural work, the 
North America Guidelines for Children's Agricultural Tasks (NAGCAT) were developed, providing voluntary age standards for 62 tasks commonly performed by children [Lee and Marlenga, 1999].

On family farm operations, children are expected to work [Elder and Conger, 2000]. Agricultural work is thought to develop work ethics, teach responsibility, provide family time, and contribute to the economic sustainability of the operation [Elkind, 1993; Kelsey, 1994; Kidd et al., 1997; Lee et al., 1997; Tevis, 1997; Elder and Conger, 2000]. The potential risks of agricultural work include being exposed to agricultural machinery, livestock, chemicals, and zoonoses; and having higher potential risks of injuries, reproductive and nervous system damage, and some cancers [Perry, 2003]. Children less than 20 years old incurred an estimated 22,648 agricultural injuries in 2001 [Hendricks et al., 2005] and averaged 116 agriculture fatalities a year between 1995 and 2000 [annualized rate: 9.3 per 100,000 youth, Goldcamp et al., 2004].

Children's agricultural injuries are predictable, given the mismatch between the hazards that exist on agricultural operations and the developmental abilities of youth who play near agricultural hazards or who are assigned ageinappropriate tasks [Elkind, 1993; Lee et al., 1997; Marlenga et al., 2001a,b]. Chore assignment is often not tied to children's developmental ability; parents report being guided by their intuition, tasks they had performed as children, or expert opinion about children's readiness [Tevis, 1997]. This study examined whether parental safety beliefs were associated with agricultural chore assignment and the risk of agricultural injury.

\section{MATERIALS AND METHODS}

\section{Study Design and Subjects}

This study was based on nested case-control analyses of data collected in the Regional Rural Injury Study-II (RRIS-II) surveillance efforts in 1999 and 2001. The RRIS-II, Phase 1 and 2 studies were designed to identify the incidence and consequences of, and risk factors for, children's agricultural injuries [Gerberich et al., 2003a,b, 2004; Ryan et al., 2004; Larson-Bright et al., 2007]. RRIS-II materials are available at http://enhs.umn.edu/riprc/riprc. html. Informed consent was obtained from each subject or their legal guardian; approval for the study was obtained from the University of Minnesota, Institutional Review Board, Human Subjects Committee.

A random sample of 16,000 agricultural operations $(3,200)$ from each participating state (Minnesota, Wisconsin, North Dakota, South Dakota, and Nebraska) was generated from the U.S. Department of Agriculture's National Agricultural Statistics Service (NASS) Master ListFrame of Agricultural Operations for each data collection year.
Households were eligible if, as of January 1 (1999/2001), they actively farmed or ranched, included children younger than 20 years of age in residence, and had produced at least $\$ 1,000$ of agricultural goods in the prior year, or participated in a Conservation Reserve Program (CRP).

Cases $(n=425)$ and controls $(n=1886)$ were children younger than 20 years of age, identified from the RRIS-II database. Children with agricultural injury events reported in the ascertainment period were selected as cases. Children without reported agricultural injury events were selected as controls using an incidence density sampling scheme based on months contributing person-time at risk. Agricultural injuries were defined as events incurred as a result of performing, or being near, an activity related to the agricultural operation that resulted in one or more of the following: restriction from normal activities for 4 or more hours; loss of consciousness or awareness, or amnesia for any length of time; or use of professional health care.

\section{Data Collection}

Computer-assisted telephone interviews were conducted by NASS interviewers for each 6-month period of each study year to ascertain injury incidence and relevant consequences. Case exposures were ascertained for the month prior to injury occurrence; control exposures were ascertained for a random 1-month period within the study period, based on an algorithm of expected injury occurrence [Gerberich et al., 1993, 2003b, 2004].

\section{Measures}

Three dimensions of parental safety beliefs were measured:

\section{Monitoring}

Beliefs about the importance of supervision were based on parents' estimation of their strictness about where their children were and who their children were with in the previous month. Parents responded to four-point Likert scales, with options of (1) not strict through (4) very strict. Cronbach's alpha $=0.84$, was calculated for the monitoring scale, indicating high internal reliability based on the interitem correlation.

\section{Importance of task readiness}

Two constructs measured parental beliefs about the importance of developmental characteristics when deciding whether children were ready to perform a new chore on the operation. Beliefs about the importance of children's age and size were summed as an indicator of the importance of children's "physical readiness." Beliefs about the 
importance of children's maturity and skills were summed as an indicator of the importance of "cognitive readiness." Parents responded to four-point Likert scales, with options of (1) not important through (4) very important. Higher scores reflected more conservative attitudes about when a child was ready to perform a new task. Cronbach's alphas for physical and cognitive readiness were 0.63 and 0.59 , respectively, indicating moderate internal reliability.

In addition to childhood agricultural injury, the following work practices, reflecting parental chore assignments, were modeled as dependent variables.

\section{Performing work}

A dichotomous variable (yes/no) based on parents' response to the question, "During the [prior month] did [your child] work in any type of activities or do chores related to your operation?"

\section{Number of chores}

The summed number of the different types of agricultural chores each child performed in the previous month, out of a possible 18 chore types. Possible chore types included all chores performed by $10 \%$ or more of the children in the study: working with beef and dairy cattle (calving, feeding, cleaning, herding), swine, horses, and poultry; operating vehicles (tractor, car, truck, motor cycle, ATV, snow mobile, other large equipment); using hand and/or power tools; and working in storage structures or with agricultural chemicals.

\section{Average hours worked per week}

The hours per week children worked on their agricultural operations reflected weekly employment patterns: $<11 \mathrm{hr}$, $11-30 \mathrm{hr}, 31-40 \mathrm{hr}, 41-60 \mathrm{hr}$, and more than $60 \mathrm{hr}$.

\section{Working early}

Children performing tasks when younger than recommended were designated as working "early." The NAGCAT age recommendations for task performance with intermittent supervision [Lee and Marlenga, 1999] were used as the standard for developmentally appropriate work for most tasks. The minimum age for calving, working with bulls, small power tools, and handling chemicals was set at 16 years of age, based on their inclusion in the Hazardous Occupations Order for Agriculture (HOOA) [USDOL, 1984]. The minimum age for operating motor vehicles was 15 years of age, based on state motor vehicle licensing requirements. Differences between recommended ages of task performance and children's actual ages were calculated to indicate the developmental gap between each task and children's physical, cognitive, and behavioral maturity.

Parent-related covariates included averaged ages, mothers' highest level of education, number of children in household, and hours per week worked on their agricultural operation. Child-related covariates included age, gender, self control and size for age.

\section{Self-control}

As existing instruments were too long to include as embedded scales, the self-control items were based on items from widely used child behavior assessment instruments: the Parent Observation of Child Adaptation (POCA) [Kellam et al., 1975]; Child Behavior Checklist [Achenbach and Edelbroch, 1991]; BASC Monitor for ADHD [Kamphaus and Reynolds, 1998]; and multidimensional personality scales [Tellegen, 1982]. The behavioral characteristics in children older than 5 years old were summed. Parents responded to four-point Likert scales, with options of (1) almost never through (4) almost always about how their child: "paid attention"; "had good concentration"; "was cautious"; "worked hard"; "was easily distracted"; "broke rules"; "was impulsive"; and "acted without thinking" (the last four items were reverse-scored). Cronbach's alpha $=0.78$ was calculated for the self-control scale, indicating high internal reliability based on the inter-item correlation.

\section{Size-for-age}

Percentile values for height-for-age and body-mass index (BMI) were generated, comparing each child against national measurements of children of the same age and gender [NCHS, 2000]. The height percentiles were grouped into "short" ( $\leq 5$ th $)$ and "not short" ( $>5$ th to 100$)$; BMI percentiles were grouped into "underweight" ( $\leq 5$ th $)$, "normal" ( $>5$ th to 85 th), "at risk of overweight" ( $>85$ th to 95th), and overweight ( $>95$ th to 100) [CDCP, 2005].

Child/household prior injuries were identified as prior agricultural injuries experienced by the child or by household members, other than the child.

\section{Data Analysis}

A causal model, based on hypothesized associations between agricultural work practices, relevant covariates, and childhood agricultural injury, served as the basis for data analysis (Fig. 1). Parental monitoring and children's work practices were differentially distributed by year of participation. An indicator was included in all multivariate analyses to adjust for these differences and for factors represented by declines, between 1998 and 2001, in the rate of agricultural injuries to males aged $0-19$ and in the number 


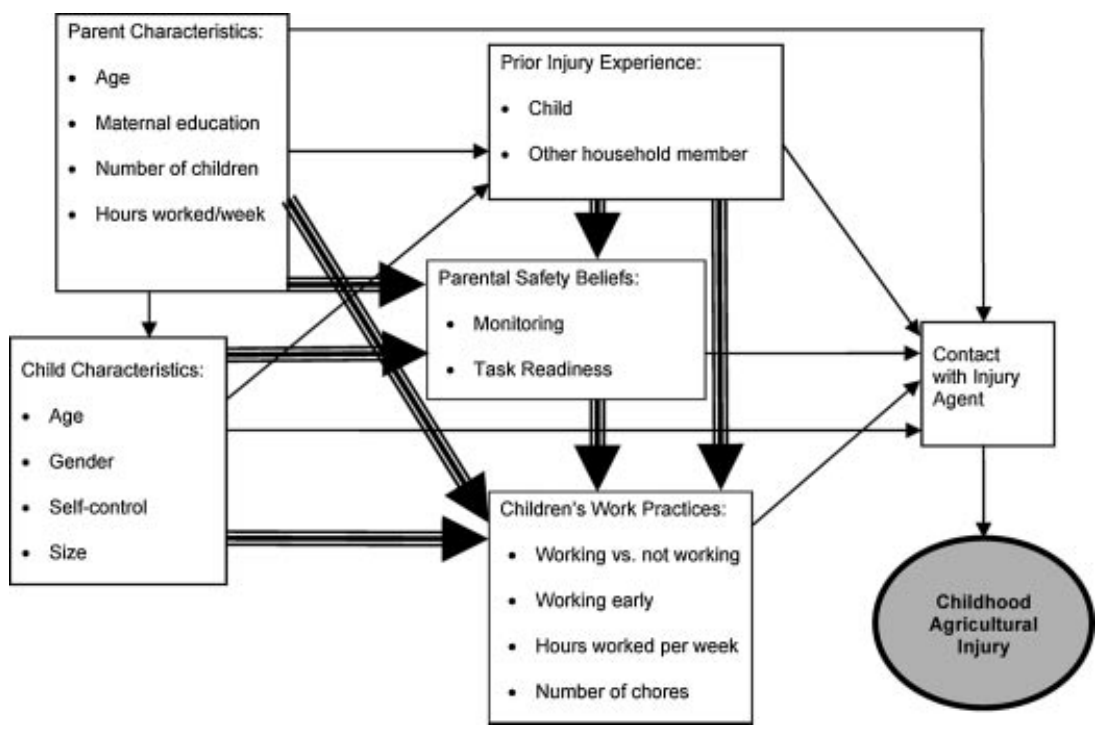

FIGURE 1. Conceptualmodel—parental safety beliefs and childhoodagriculturalinjury.Thick tripleline $=$ Effectof variableatarrow headismodified by the variable at the arrow tail. Note:Year of participation(1999/2001) isincluded inall statistical models butisnotshown here.

of injuries to all youths living on U.S. operations [Hendricks et al., 2005].

Odds ratios (ORs) and 95\% confidence intervals (95\% CI) estimating the risk of agricultural injury and "performing agricultural work" were calculated for each exposure using multivariate logistic regression. Interaction terms were constructed for each safety belief-covariate pair and tested for significance. Beta estimates $(\beta)$ and $95 \%$ CI evaluated the likelihood of chore assignment (hours worked, performing chores, and working early) and child and family characteristics per unit change in the safety belief variables.

Among the 32,000 agricultural operations sampled, $6,250(20 \%)$ could not be screened, 16,940 (53\%) were screened and found ineligible, and 8,810 (28\%) were found eligible. Of the eligible operations, 7,420 (84\%) participated in the full study. Non-response bias was controlled by inversely weighting responses by estimated probabilities of response [Horvitz and Thompson, 1952], estimated as a function of characteristics from the U.S. Department of Agriculture's National Agricultural Statistics Service database (state, type of operation, annual revenue by quintiles). The unknown eligibility among non-respondents was controlled by down-weighting each sample member by the estimated probability of eligibility among the respondents with the same characteristics [Mongin, 2001].

\section{RESULTS}

Youth participant and parent characteristics, based on case-control status, are identified in Table I. As shown in Table II, children were at decreased risk of childhood agricultural injury if their parents reported "moderate" versus "very strict" monitoring or if parents reported that cognitive and physical readiness were important considerations when assigning new chores; the associations between safety beliefs and decreased injury risk were stronger for working age children ( $7-16$ years old). Parental safety beliefs were not associated with the chore assignments measured in this study (not shown).

The interaction of cognitive readiness with parental age was statistically significant. For most children, parental beliefs about the importance of cognitive readiness when assigning a child an agricultural task was associated with decreased injury risk. For children whose parents were aged 39-44, the risk was elevated, but not statistically significant $(\mathrm{OR}=1.7,95 \% \mathrm{CI}=0.7-3.9)$. For children aged $0-19$ years old, having parents who believed that cognitive readiness was important decreased the injury risk for girls, but not for boys. For working aged children ( $7-16$ years old), parental beliefs about the importance of cognitive readiness decreased the injury risk for both genders.

When associations with safety belief were examined, the three safety beliefs were positively associated with each other (Table III). Increased parental monitoring was associated with being younger than 16 years old, a 2001 respondent, and having parents who did not work on the operation. Decreased monitoring was associated with children sometimes exhibiting self-control, having older parents, and having parents who worked more than $60 \mathrm{hr}$ a week. Being 10-11 years old and maternal college education were associated with parental beliefs about the increased importance of cognitive readiness. Being 6-9 years old was associated with parental beliefs about the increased importance of physical readiness. Low levels of self-control 
TABLE I. Respondent Characteristics and Exposures $(\mathrm{N}=2,311)$

\begin{tabular}{|c|c|c|}
\hline & \multicolumn{2}{|c|}{ No. $(\%)$ of respondents } \\
\hline & $\begin{array}{l}\text { Case events } \\
(\mathrm{N}=425)\end{array}$ & $\begin{array}{c}\text { Controls } \\
(\mathrm{N}=\mathbf{1 , 8 8 6})\end{array}$ \\
\hline \multicolumn{3}{|l|}{ Data collection year } \\
\hline 1999 Respondents & $203(47.8)$ & $755(40.0)$ \\
\hline 2001Respondents & $222(52.2)$ & $1131(60.0)$ \\
\hline \multicolumn{3}{|l|}{ Child characteristics } \\
\hline \multicolumn{3}{|l|}{ Gender } \\
\hline Female & $133(31.3)$ & $843(44.7)$ \\
\hline Male & $292(68.7)$ & $1043(55.3)$ \\
\hline \multicolumn{3}{|l|}{ Age groups $^{\mathrm{a}}$} \\
\hline $0-5$ & $46(10.8)$ & $324(17.2)$ \\
\hline $6-9$ & $55(12.9)$ & $306(16.3)$ \\
\hline $10-11$ & $48(11.3)$ & $213(11.3)$ \\
\hline $12-13$ & $90(21.2)$ & $206(10.9)$ \\
\hline $14-15$ & $68(16.0)$ & $248(13.2)$ \\
\hline $16-19$ & $118(27.8)$ & $586(31.1)$ \\
\hline \multicolumn{3}{|l|}{ Self-control ${ }^{b}$} \\
\hline Almost never & $21(5.6)$ & $51(3.3)$ \\
\hline Sometimes & $10(2.7)$ & $96(6.3)$ \\
\hline Often & $83(22.3)$ & $273(17.9)$ \\
\hline Almost always & $258(69.4)$ & $1106(72.5)$ \\
\hline \multicolumn{3}{|c|}{ Height-for-age (percentile groups) ${ }^{c}$} \\
\hline Short $(<5)$ & $28(6.9)$ & $132(7.7)$ \\
\hline Not short $(5-100)$ & $378(93.1)$ & $1593(92.4)$ \\
\hline \multicolumn{3}{|c|}{${\text { Body-mass-index-for-age } \text { (percentile groups) }^{d}}^{d}$} \\
\hline Underweight $(0$ to $<5)$ & $21(5.1)$ & $107(6.2)$ \\
\hline Normal $(5$ to $<85)$ & $243(59.4)$ & $1044(60.3)$ \\
\hline Overweight risk $(85$ to $<95)$ & $79(19.3)$ & $262(15.1)$ \\
\hline Overweight $(95-100)$ & $66(16.1)$ & $317(18.3)$ \\
\hline \multicolumn{3}{|l|}{ Prior children’s injuries } \\
\hline No prior injury & $310(72.9)$ & $1710(90.7)$ \\
\hline 1 & $59(13.9)$ & $142(7.5)$ \\
\hline 2 & $28(6.6)$ & $17(0.9)$ \\
\hline $3-4$ & $16(3.8)$ & $11(0.6)$ \\
\hline$>5$ & $12(2.8)$ & $6(0.3)$ \\
\hline \multicolumn{3}{|l|}{ Parent characteristics } \\
\hline \multicolumn{3}{|l|}{ Parents' average age $^{\mathrm{a}}$} \\
\hline Median (years) & 41.5 & 42.0 \\
\hline Range & $24.5-61$ & $22.5-84$ \\
\hline \multicolumn{3}{|l|}{ Maternal educational status ${ }^{\mathrm{e}}$} \\
\hline Less than high-school & $7(1.7)$ & $32(1.8)$ \\
\hline High school graduate & $128(31.3)$ & $553(31.3)$ \\
\hline Technical school & $55(13.4)$ & $264(15.0)$ \\
\hline College & $219(53.5)$ & $915(51.9)$ \\
\hline \multicolumn{3}{|l|}{ Number of children in household ${ }^{a}$} \\
\hline Median & 3 & 2 \\
\hline Range & $1-10$ & $1-9$ \\
\hline \multicolumn{3}{|c|}{ Hours per week parents worked on own operation ${ }^{\mathrm{a}}$} \\
\hline $0 \mathrm{hr}$ & $10(2.4)$ & $8(0.4)$ \\
\hline $1-10 \mathrm{hr}$ & $13(3.1)$ & $159(8.7)$ \\
\hline
\end{tabular}

TABLE I. (Continued)

\begin{tabular}{lcc} 
& \multicolumn{2}{c}{ No. (\%) of respondents } \\
\cline { 2 - 3 } & $\begin{array}{c}\text { Case events } \\
\text { (N }=\mathbf{4 2 5})\end{array}$ & $\begin{array}{c}\text { Controls } \\
\text { (N=1,886) }\end{array}$ \\
\hline $11-30 \mathrm{hr}$ & $108(25.4)$ & $639(35.0)$ \\
$31-40 \mathrm{hr}$ & $95(22.4)$ & $402(22.0)$ \\
$41-60 \mathrm{hr}$ & $132(31.1)$ & $468(25.6)$ \\
$60+\mathrm{hr}$ & $67(15.8)$ & $152(8.3)$ \\
Median Hours & 39.5 & 32.7 \\
Range & $2.25-113.1$ & $0-115.8$ \\
Prior household members' injuries & & \\
No prior injury & $109(25.7)$ & $817(43.3)$ \\
1 & $54(12.7)$ & $397(21.1)$ \\
2 & $49(11.5)$ & $230(12.2)$ \\
$3-5$ & $100(23.5)$ & $254(13.5)$ \\
$>6$ & $113(26.6)$ & $188(10.0)$ \\
\hline
\end{tabular}

a Less than $5 \%$ of the data were missing.

${ }^{b}$ Data on self-control were missing for $12.5 \%$ of the cases and $19.1 \%$ of the controls.

${ }^{c}$ Data on size-for-age were missing for $4.5 \%$ of the cases and $8.5 \%$ of the controls.

${ }^{\mathrm{d}}$ Data on body-mass-index-for-age were missing for $3.8 \%$ of the cases and $8.3 \%$ of the controls.

${ }^{e}$ Data on maternal education were missing for $3.8 \%$ of the cases and $6.5 \%$ of the controls.

were associated with decreased importance of both physical and cognitive readiness. Having five or more prior agricultural injuries was associated with decreased importance of cognitive readiness.

\section{DISCUSSION}

Supervision is a fundamental parenting strategy, used to keep children safe. Although prior research suggests that supervision is protective for injuries, in general [Peterson et al., 1987; Morrongiello et al., 2001; Morrongiello and House, 2004], on the agricultural worksite, proximity to a parent may be associated with increased risk of injury [Morrongiello et al., 2008].

In the current study, "moderate" versus "very strict" parental monitoring was associated with a reduced risk of childhood agricultural injury. The risk of injury associated with "very strict" monitoring may reflect increased proximity to a working parent or that parental monitoring is associated with factors related to how parents perceive children's vulnerability or risk. For example, children's gender modified the association between parental beliefs and injury - the importance of cognitive readiness was associated with decreased injury for girls, but not boys. The association may be influenced by other gender-related effects, such as parental reactions to risk-taking in sons [Bijttebier et al., 2003] or expectations of earlier autonomy 
TABLE II. Parents' Safety Beliefs: Association With Childhood Agricultural Injury

No. (\%) of respondents

\begin{tabular}{|c|c|c|c|}
\hline \multirow[b]{2}{*}{$0-19$ Years of age $(N=2,311)$} & & \multirow[b]{2}{*}{ Odds ratio ${ }^{b}$ ( $95 \%$ confidence interval) } \\
\hline & Case events $(N=425)$ & Controls $(N=1,886)$ & \\
\hline \multicolumn{4}{|l|}{ Monitoring $^{\mathrm{a}}$} \\
\hline Not—somewhat & $41(10.0)$ & $155(8.7)$ & $1.1(0.7-1.6)$ \\
\hline Moderate & $70(16.7)$ & $386(21.6)$ & $0.7(0.5-0.97)$ \\
\hline Very & $302(73.4)$ & $1243(69.7)$ & Reference \\
\hline \multicolumn{4}{|l|}{ Cognitive task readiness: maturity/skills ${ }^{\mathrm{a}}$} \\
\hline All children & $416(50.0)$ & $1855(50.0)$ & $0.9(0.7-1.1)$ \\
\hline Males only & $286(15.6)$ & $1029(22.3)$ & $1.2(0.9-1.6)$ \\
\hline Females only & $130(34.4)$ & $826(27.7)$ & $0.5(0.4-0.8)$ \\
\hline Interaction term: cognitive $\times$ gender & & & Wald $\mathrm{X}^{2}=3.8 ; P$-value $=0.052$ \\
\hline Interaction term: cognitive $\times$ parent age & & & Wald $X^{2}=3.9 ; P$-value $=0.048$ \\
\hline Median value & 4.0 & 4.0 & \\
\hline Range & $1.5-4$ & $1-4$ & \\
\hline \multicolumn{4}{|l|}{ Physical task readiness: age/size ${ }^{a}$} \\
\hline All children & 417 & 1855 & $0.9(0.7-0.99)$ \\
\hline Median value & 3.5 & 3.5 & \\
\hline Range & $1-4$ & $1-4$ & \\
\hline $7-16$ Years of age & $(\mathrm{N}=287)$ & $(\mathrm{N}=1044)$ & \\
\hline \multicolumn{4}{|l|}{ Monitoring $^{\mathrm{a}}$} \\
\hline Not—somewhat & $19(6.6)$ & $54(5.2)$ & $1.1(0.6-2.1)$ \\
\hline Moderate & $40(13.9)$ & $195(18.7)$ & $0.6(0.4-0.9)$ \\
\hline Very & $222(77.4)$ & $769(73.7)$ & Reference \\
\hline \multicolumn{4}{|l|}{ Cognitive task readiness: maturity/skills ${ }^{\mathrm{a}}$} \\
\hline All children & $279(50.0)$ & $1025(50.0)$ & $0.7(0.5-0.9)$ \\
\hline Males only & $192(34.0)$ & $572(28.0)$ & $1.1(0.7-1.6)$ \\
\hline Females only & $87(15.6)$ & $453(22.1)$ & $0.3(0.2-0.5)$ \\
\hline Median value & 4.0 & 4.0 & \\
\hline Range & $1.5-4$ & $1.5-4$ & \\
\hline \multicolumn{4}{|l|}{ Physical task readiness: age/size ${ }^{a}$} \\
\hline All children & 280 & 1025 & $0.8(0.6-0.95)$ \\
\hline Median value & 3.0 & 3.5 & \\
\hline Range & $1-4$ & $1-4$ & \\
\hline
\end{tabular}

aLess than $5 \%$ of the data were missing.

${ }^{b}$ Separate multivariable logistic regression analyses were performed for each exposure variable. The statistical models adjusted for: missing values, non-response, year participated, age, gender, BMI, short, self-control, prior child injuries, prior injuries to household members, parents' age, maternal education, children in household, hours per week parents worked.

and maturity from daughters [Dekovic et al., 1997]. The mechanism warrants further research, as the rate of agricultural injuries among girls aged $10-15$ years old living on agricultural operations more than doubled between 1998 and 2001 [Hendricks et al., 2005].

Safety beliefs were expected to be associated with chore assignment. No association was found in this study, suggesting that the protective association between safety beliefs and injury was not mediated by the work practices that were measured. Similar disconnects are supported by recent research examining associations between parental knowledge and perceptions and NAGCAT guidelines. Pickett et al. [2003] identified that, although parents' knowledge of child development was associated with more frequent use of the NAGCAT age guidelines and fewer age violations when assigning tractor work, $20 \%$ of parents with perfect knowledge scores assigned chores that violated age guidelines. Zentner et al. [2005] reported that, although parental risk perceptions were weakly associated with making safety changes and using NAGCAT guidelines, $48 \%$ of parents with appropriate risk perceptions were not using these guidelines.

Safety beliefs may also be associated with underlying parenting processes or attributes, such as parents' conscientiousness, being well organized, and having high standards 
TABLE III. Characteristics Associated With Parents' Safety Beliefs (Multivariable Linear Regression [N=2,311])

Types of parental safety beliefs ${ }^{\mathrm{g}}$

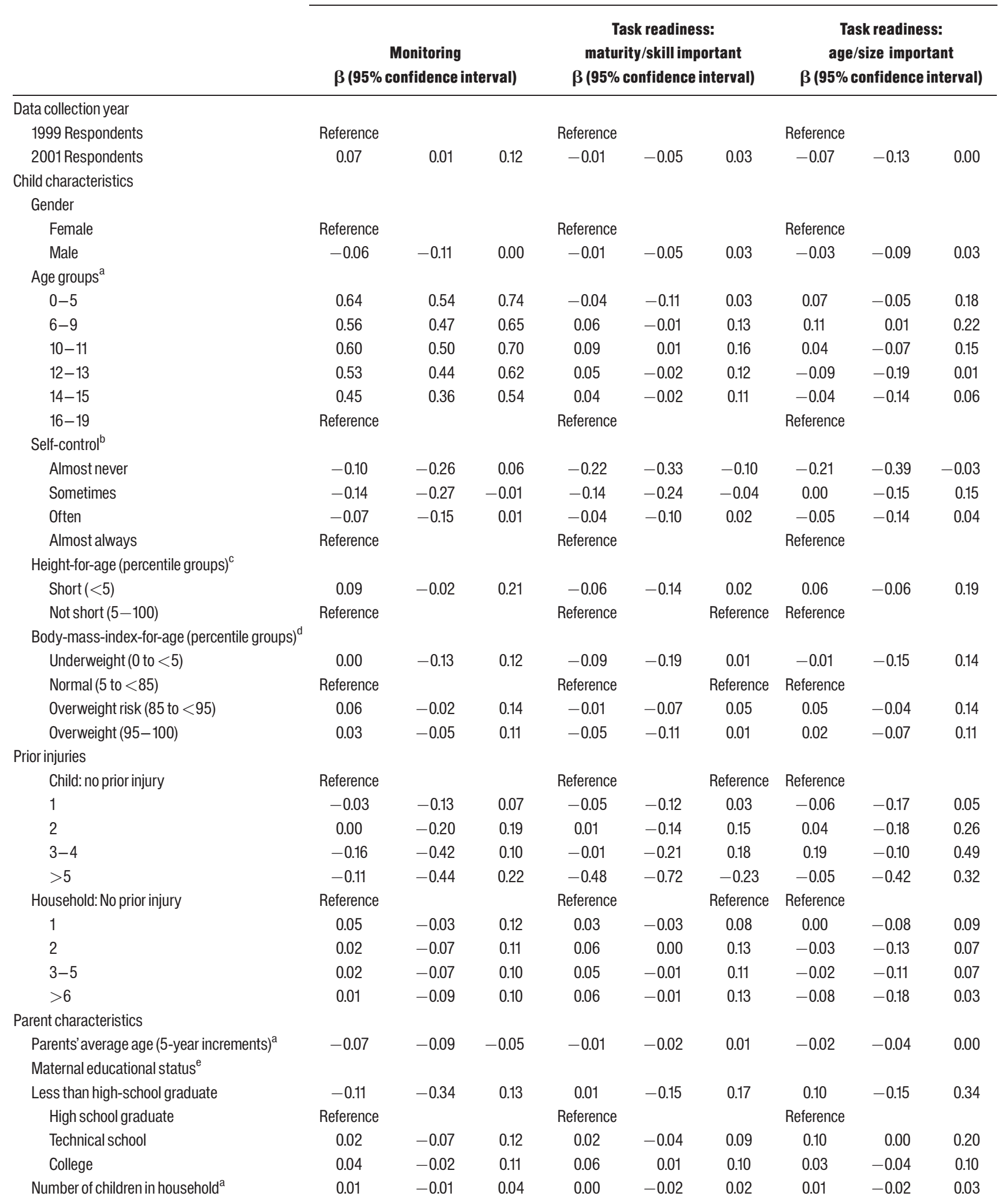


TABLE III. (Continued)

\begin{tabular}{|c|c|c|c|c|c|c|c|c|c|}
\hline & \multicolumn{9}{|c|}{ Types of parental safety beliefs ${ }^{g}$} \\
\hline & \multicolumn{3}{|c|}{$\begin{array}{c}\text { Monitoring } \\
\beta(95 \% \text { confidence interval) }\end{array}$} & \multicolumn{3}{|c|}{$\begin{array}{c}\text { Task readiness: maturity/skill } \\
\text { important } \beta \text { ( } 95 \% \text { confidence } \\
\text { interval) }\end{array}$} & \multicolumn{3}{|c|}{$\begin{array}{c}\text { Task readiness: age/size } \\
\text { important } \beta \text { ( } 95 \% \text { confidence } \\
\text { interval) }\end{array}$} \\
\hline \multicolumn{10}{|c|}{ Hours per week parents worked on own operation ${ }^{\mathrm{a}}$} \\
\hline $0 \mathrm{hr}$ & 0.48 & 0.01 & 0.95 & -0.02 & -0.35 & 0.31 & -0.29 & -0.79 & 0.21 \\
\hline $1-10 \mathrm{hr}$ & -0.02 & -0.15 & 0.10 & -0.09 & -0.17 & 0.00 & 0.01 & -0.12 & 0.13 \\
\hline $11-30 \mathrm{hr}$ & 0.01 & -0.07 & 0.08 & -0.03 & -0.08 & 0.03 & -0.01 & -0.09 & 0.07 \\
\hline $31-40 \mathrm{hr}$ & -0.02 & -0.10 & 0.07 & -0.01 & -0.07 & 0.05 & -0.01 & -0.10 & 0.08 \\
\hline $41-60 \mathrm{hr}$ & Reference & & & Reference & & & Reference & & \\
\hline $60+\mathrm{hr}$ & -0.11 & -0.22 & -0.01 & 0.02 & -0.06 & 0.09 & -0.07 & -0.19 & 0.04 \\
\hline \multicolumn{10}{|l|}{ Strictness ${ }^{\dagger}$} \\
\hline Not—somewhat & - & & - & -0.25 & -0.32 & -0.17 & -0.20 & -0.32 & -0.09 \\
\hline Moderate & - & & - & -0.11 & -0.16 & -0.05 & -0.07 & -0.16 & 0.01 \\
\hline Very & - & & - & Reference & & & Reference & & \\
\hline Task readiness: maturity/skills ${ }^{a}$ & 0.20 & 0.14 & 0.25 & - & & - & 0.36 & 0.30 & 0.42 \\
\hline Task readiness: age/size ${ }^{\mathrm{a}}$ & 0.07 & 0.03 & 0.10 & 0.16 & 0.13 & 0.18 & - & & - \\
\hline
\end{tabular}

aLess than $5 \%$ of the data were missing.

${ }^{b}$ Data on self-control were missing for $12.5 \%$ of the cases and $19.1 \%$ of the controls.

${ }^{\mathrm{c}}$ Data on size-for-age were missing for $4.5 \%$ of the cases and $8.5 \%$ of the controls.

dData on BMI-for-age were missing for $3.8 \%$ of the cases and $8.3 \%$ of the controls.

${ }^{\mathrm{e}}$ Maternal education data were missing for $3.8 \%$ of the cases and $6.5 \%$ of the controls.

${ }^{\mathrm{f}}$ Data on monitoring were missing for $5.4 \%$ of the cases and $9.5 \%$ of the controls.

${ }^{9}$ Separate multivariable linear regression analyses were performed for each covariate, for each safety belief. The statistical models were adjusted for case-control status and the following covariates: Gender — adjusted for: missing values, non-response, year participated, age, parents' age, maternal education, children in household, hours parents worked. Child's age — adjusted for: missing values, non-response, year participated, gender, parents' age and hours worked, maternal education, children in household. Self-control—adjusted for: missing values, non-response, year participated, gender, age, parents' age and hours worked, maternal education, household children. Short-for-age — adjusted for: missing values, non-response, year participated, gender, age, parents' age and hours worked, maternal education, household children. Body-mass index (BMI)-for-age — adjusted for: missing values, non-response, year participated, gender, age, parents' age, maternal education, children in household, hours per week parents worked. Prior child injuries_adjusted for: missing values, non-response, year participated, gender, age, BMl, short, self-control, parents' age, maternal education, children in household, hours per week parents worked, prior injuries to household members. Year participated—adjusted for: missing values, non-response, age, gender. Parents' age — adjusted for: non-response, year participated. Maternal education—adjusted for: missing values, non-response, year participated, parents' age, hours per week parents worked, children in household. Children in household — adjusted for: missing values, non-response, year participated, parents' age, maternal education, hours per week parents worked. Hours per week parents worked—adjusted for: missing values, non-response, year participated, parents' age, maternal education, children in household. Prior injuries to household members_-adjusted for: missing values, non-response, year participated, age, gender, BMl, short, self-control, prior child injuries, parents' age, maternal education, children in household, hours per week parents worked.

that better predict children's injuries than do specific parenting practices or supervisory behaviors [Morrongiello, 2005]. For example, in the current study, parents who believed that task readiness was important may have also managed risk by providing "scaffolding," defined by Masten [2007], as extra support during periods of vulnerability, when children are asked to perform new tasks but are not developmentally able to execute them safely.

Determinants of parents' safety and child development beliefs are infrequently examined, although associations with socio-economic variables have been previously suggested. Rivara and Howard [1982] found child development knowledge was positively correlated with parents' education levels and their safety knowledge and was negatively associated with the number of children in the family. Pickett et al. [2003] found that higher child development knowledge scores were associated with parents who were younger, better educated, and female. In the current study, maternal college education was associated with increased importance of cognitive readiness; parents not working on the operation was associated with increased monitoring; parental work weeks of 60 or more hours were associated with decreased monitoring; and parental work weeks of 1-10 hr were associated with decreased importance of cognitive readiness.

Limitations of this analysis include using self-reported injury and exposure data collected during the same interview. Recall bias was minimized by limiting recall of injury events to the previous 6 months [Braun et al., 1994; Gerberich et al., 2004] and recall of exposures to a 1-month period within the 
previous year [Lee et al., 1999]. The results were also subject to the following assumptions. Monitoring, a measure of parents' knowledge about children's activities, was used in this study as an indicator of parents' supervisory behavior; the correlation between monitoring and the actual supervision of agricultural tasks was unknown and could not be adjusted for in this analysis. Measurement error in parental safety beliefs or children's work practices could have contributed to the lack of association observed between them; parental perceptions related to safety beliefs could have been biased by injury experience.

\section{CONCLUSIONS}

This study is the first to use population-based casecontrol data to examine the risk of agricultural injury associated with parental safety beliefs and the association between safety beliefs and chore assignment. Moderate levels of monitoring and increased importance of cognitive and physical readiness were associated with decreased risk of childhood agricultural injury; safety beliefs were not associated with the assignment of agricultural chores. Of note, parental belief about the importance of cognitive readiness was most protective for daughters. The results serve as the basis for future analytical studies of parenting-related mechanisms associated with the risk of childhood agricultural injury and for ultimate development of appropriate prevention and control efforts.

\section{ACKNOWLEDGMENTS}

Support for this effort and for the Regional Rural Injury Study-II was provided, in part, by the National Institute for Occupational Safety and Health (NIOSH), Centers for Disease Control and Prevention, Department of Health and Human Services (RO1 CCR514375; R01 OHO4270); the Occupational Injury Prevention Research Training Program and the National Occupational Research Agenda, Midwest Center for Occupational Health and Safety (NIOSH T42/ CCT510-422), University of Minnesota, Minneapolis, Minnesota, U.S.A.; and the Regional Injury Prevention Research Center, Division of Environmental Health Sciences, School of Public Health, University of Minnesota, Minneapolis, Minnesota, U.S.A. Collaborating organizations included the U.S. Department of Agriculture's National Agricultural Statistics Service offices in the five participating states of Minnesota, Wisconsin, North Dakota, South Dakota, and Nebraska, and the respective Agricultural Extension Services and state representatives. Most importantly, without the interest of, and commitments made by, the households selected in the five-state region, this effort would have not been possible.

\section{REFERENCES}

Achenbach TM, Edelbroch CS. 1991. Manual for the Child Behavior Checklist and Revised Child Behavior Profile. Burlington, VT: University Associates in Psychiatry.

Bijttebier P, Vertommen H, Florentie K. 2003. Risk-taking behavior as a mediator of the relationship between children's temperament and injury liability. Psychol Health 18(5):645-653.

Braun BL, Gerberich SG, Sidney S. 1994. Injury reports: Utility of self report in retrospective identification in the U.S.A. J Epidemiol Community Health 49:604-605.

Centers for Disease Control and Prevention (CDCP). 2005. BMI-Body Mass Index: BMI for Children and Teens. Available at www.cdc.gov/ nccdphp/dnpa/bmi/bmi-for-age.htm. Accessed 06/28/2005.

Dekovic M, Noom M, Meeus W. 1997. Expectations regarding development during adolescence: Parental and adolescent perceptions. J Youth Adolesc 26:253-272.

Elder GH, Conger RD. 2000. Children of the land: Adversity and success in rural America. Chicago: University of Chicago Press.

Elkind PD. 1993. Correspondence between knowledge, attitudes, and behavior in farm health and safety practices. J Saf Res 24:171-179.

Gerberich SG, Gibson RW, French LR, Carr P, Renier CM, Gunderson PD, Martin F, True JA, Shutske J, Brademeyer K. 1993. The Regional Rural Injury Study-I (RRIS-I): A Population-Based Effort. A Report to the Centers for Disease Control (NTIS\# PB94-134848). Minneapolis: Regional Injury Prevention Research Center.

Gerberich SG, Church TR, Renier CM, Gibson RW, French LR, Masten AS, Mongin SJ, Ferguson K, Alexander BH, Ryan A, Zhang X. 2003a. Injury surveillance: Incorporation of a case-control design. Am J Epidemiol 157(11):51.

Gerberich SG, Gibson RW, French LR, Church TR, Alexander BH, Shutske J, Masten AS, Renier CM, Mongin SJ, Ryan A, Ferguson KR, Zhang X, Jensen KE. 2003b. Etiology and consequences of injuries among children in farm households: A regional rural injury study (RO1 CCR514375), Technical Report, Centers for Disease Control and Prevention. Minneapolis: Regional Injury Prevention Center, University of Minnesota.

Gerberich SG, Alexander BH, Church TR, Masten AS, Renier CM Mongin SJ, Ryan A, Ferguson KR. 2004. Regional Rural Injury StudyII, Phase 2: Agricultural Injury Surveillance (RO1/OHO4270), Technical Report, Centers for Disease Control and Prevention. Minneapolis Regional Injury Prevention Center, University of Minnesota.

Goldcamp M, Hendricks KJ, Myers JR. 2004. Farm fatalities to youth 1995-2000: A comparison by age groups. J Saf Res 35(2):151-157.

Hendricks KJ, Layne LA, Goldcamp EM, Myers JR. 2005. Injuries to youth living on U.S. farms in 2001 with comparison to 1998. J Agromedicine 10(4):19-26.

Horvitz DG, Thompson DJ. 1952. A generalization of sampling without replacement from a finite universe. J Am Stat Assoc 47:663-685.

Kamphaus RW, Reynolds CR. 1998. BASC monitor for ADHD. Circle Pines, MN: AGS Publishing.

Kellam SG, Branch JD, Agrawal KC, Ensminger ME. 1975. Menta health and going to school: The Woodlawn Program of Assessment, Early Intervention, and Evaluation. Chicago: University of Chicago Press.

Kelsey TW. 1994. The agrarian myth and policy responses to farm safety. Am J Public Health 84(7):1171-1177.

Kidd P, Townley K, Cole H, McKnight R, Piercy L. 1997. The process of chore teaching: Implications for farm youth injury. Fam Community Health 19:78-89. 
Larson-Bright M, Gerberich SG, Alexander BH, Gurney JG, Masten AS, Church TR, Ryan AD, Renier CM. 2007. Children's work practices and childhood agricultural injury. Inj Prev 13:409415 .

Lee B, Marlenga B. 1999. Professional Resource Manual: North American Guidelines for Children's Agricultural Tasks. Marshfield, WI: Marshfield Clinic.

Lee B, Jenkins LS, Westaby JD. 1997. Factors influencing exposure of children to major hazards on family farms. J Rural Health 13(3):206215 .

Lee SS, Gerberich SG, Waller LA, Anderson A, McGovern P. 1999. A case-control study of work-related assault injuries among nurses. Epidemiology 10(6):685-691.

Marlenga B, Pickett W, Berg RL. 2001a. Assignment of work involving farm tractors to children on North American farms. Am J Ind Med 40:15-22.

Marlenga B, Pickett W, Berg RL. 2001b. Agricultural work activities reported for children and youth on 498 North American farms. J Agric Saf Health 7:241-252.

Masten AS. 2007. Competence, resilience and development in adolescence: Clues for prevention science. In: Romer D, Walker E, editors. Adolescent psychopathology and the developing brain: Integrating brain and prevention science. New York: Oxford University Press. pp 31-52.

Mongin SJ. 2001. Adjustments for nonresponse in the presence of unknown eligibility. Health Studies Research Report. Division of Environmental and Occupational Health, University of Minnesota, Minneapolis. Available at http://www1.umn.edu/eoh. Accessed 03/01/ 2003.

Morrongiello BA. 2005. Caregiver supervision and child-injury risk: I. Issues in defining and measuring supervision; II. Findings and directions for future research. J Pediatr Psychol 30(7):536-552.

Morrongiello BA, House K. 2004. Measuring parent attributes and supervision behaviors relevant to child injury risk: Examining the usefulness of questionnaire measures. Inj Prev 10:114118 .

Morrongiello BA, Midgett C, Shields R. 2001. Don't run with scissors: Young children's knowledge of home safety rules. J Pediatr Psychol 26(2):105-115.
Morrongiello BA, Corbett M, McCourt M, Johnston N. 2006. Understanding unintentional injury risk in young children II. The contribution of caregiver supervision, child attributes, and parent attributes. J Pediatr Psychol 31:540-551

Morrongiello BA, Pickett W, Berg RL, Linneman JG, Brison RJ, Marlenga B. 2008. Adult supervision and pediatric injuries in the agricultural worksite. Accid Anal Prev 40:1149-1156. 10.1016/ j.aap.2007.12.007.

National Center for Health Statistics (NCHS). 2000. 2000 CDC Growth Charts: United States. Available at www.cdc.gov/nchs/about/major/ nhanes/growthcharts/. Accessed 05/20/2005.

Perry MJ. 2003. Children's agricultural health: Traumatic injuries and hazardous inorganic exposures. J Rural Health 19(3):269-278.

Peterson L, Stern BL. 1997. Family processes and child risk for injury. Behav Res Ther 35(3):179-190.

Peterson L, Farmer J, Mori L. 1987. Process analysis of injury situations: A complement to epidemiological methods. J Soc Issues 43:33-44.

Pickett W, Marlenga B, Berg RL. 2003. Parental knowledge of child development and the assignment of tractor work to children. Pediatrics 112:11-16

Rivara FP, Howard D. 1982. Parental knowledge of child development and injury risks. J Dev Behav Pediatr 3(2):103-105.

Ryan A, Mongin SJ, Gerberich SG, Renier CM, Alexander BH, Church TR, Masten AS, Ferguson K. 2004. A comparison of exposure measurements for injury rates: Regional Rural Injury Study-II. Am J Epidemiol 159(11):46.

Tellegen A. 1982. Brief Manual for the Differential Personality Questionnaire. Minneapolis, MN: University of Minnesota.

Tevis C. 1997. New survey shows farm work isn't child's play. Successful Farming 95(11):70-71.

U.S. Department of Labor (USDOL). 1984. Child Labor Requirements in Agriculture Under the Fair Labor Standards Act. Child Labor Bulletin No. 102. Washington, D.C.: U.S. Department of Labor, Employment Standards Administration, Wage and Hour Division. WH Publication 1295. U.S. Government Printing Office: 1989-241-406/06551.

Zentner J, Berg RL, Pickett W, Marlenga B. 2005. Do parent's perceptions of risks protect children engaged in farm work? Prev Med 40:860-866. 